Serials Review Vol. 23, NO. 1 (SPRING 1997)

(C) Elsevier Science

[http://www.elsevier.com/wps/find/journaldescription.cws_home/620213/description\#descriptio

n]

\title{
Serials Exchanges: Streamlining and Elimination
}

\section{Carol Pitts Diedrichs and Trisha L. Davis}

\section{Introduction}

Serial exchanges have been a fundamental component of the collection development and acquisitions programs of large research libraries, particularly those with strong programs in international studies. The most-cited rationale for exchanges is that expressed by Mark Kovacic. "The primary purpose of maintaining exchanges is the acquisition of those materials which are not available in any other way, or for which exchange is more economically advantageous than purchasing." ${ }^{1}$ Beginning as early as 1970 (if not earlier), librarians were, and continue to be, ambivalent about the desirability of acquiring material via exchange. In 1970, William Huff indicated that $95 \%$ of the ARL libraries he surveyed had gift and exchange programs in operation. "Attitudes toward the programs were, on the whole, ambivalent. Many librarians thought it was useful, especially since it sometimes was the only way to obtain some serials; however, more believed the program did not pay its own way." ${ }^{2}$ In 1979, Pamela Bluh and Virginia C. Haines expressed concern about exchange programs in light of fiscal responsibility and collection development:

"The exchange of publications between American and foreign libraries has been the subject of numerous articles, yet little has been written about the topic as it relates to current concepts of fiscal responsibility and collection development activities. In this time of austerity, it seems appropriate that the exchange agreement as an alternative means of acquisition should be reviewed, so that the philosophical and practical considerations of exchanges can be examined to determine if this method continues to be viable." ${ }^{3}$

Bluh and Haines's review of their exchanges resulted in a reduction from 390 exchange partners (more than 800 titles) to 250 exchange agreements (555 titles). The number of subscriptions acquired for these partners was also reduced from 660 to $325 .{ }^{4}$ In beginning her article on evaluating the costs of domestic serials exchanges, Priscilla C. Yu stated that "libraries in the 1980s face even more serious economic dilemmas than in the 1970s." ${ }^{5}$ The 1990s have been no better for libraries, with rapid increases in the cost of books and journals, as well as budget cuts, resulting in reduced staffing resources.

This article will examine the circumstances that led The Ohio State University (OSU) Libraries' Acquisition Department to undertake a multiyear project to evaluate and eliminate serial exchanges whenever feasible. The paper will also describe the project design and its goals, 
the problems encountered, and the time line. The final section will evaluate the results and provide a statistical analysis.

\section{Background}

The Ohio State University Libraries has had a long history of support for serial exchanges. This commitment was facilitated in the 1980s by a University-level emphasis on international programs. Through the office of the Vice Provost for International Affairs, eight staff positions within the Libraries were funded (six at 100\% and two at 50\%). These positions were primarily for language specialists/bibliographers and their staff. One of these staff positions, however, was assigned exclusively to the Acquisition Department for the maintenance of the serial exchange program. Strings were definitely attached to these positions, as is revealed in a letter from Vice-Provost Francille M. Firebaugh in 1988: "the purpose of the Office of Academic Affairs in providing departments with funds for personnel through International Affairs is to strengthen the University's international academic dimensions, and your cooperation in this effort is deeply appreciated. Should these positions become vacant, our office should be notified immediately.", 6

The Libraries had extended this commitment in the late 1980s by regularly requesting the addition of a fulltime gifts and exchanges librarian in its annual budget request. One of the rationales for this additional resource was the belief that focus on the exchange process could increase the journal list of the Libraries, which was considered deficient for a library of its size. With the arrival of one of the authors in 1987 (Carol Diedrichs), more investigation began into the feasibility of such a position. The status of exchange operations in large academic research libraries as recorded in the literature at that time follows:

1. the average number of staff devoted to exchanges was one professional and two paraprofessionals; $^{7}$

2. in the mid-1980s staffing for exchanges was being reduced due to budget cuts; ${ }^{8}$

3. by 1989 a study by Carl Deal of thirteen libraries known to have significant exchange programs reflected a changing pattern.

a. No library surveyed had a total of one FTE or more in professional time from all units maintaining gifts and exchanges.

b. Only seven libraries reported any student assistance.

c. Only three libraries devoted two or more FTE of support staff for gifts and exchange.

d. Five libraries devoted less than one FTE of staff.

e. The average number of staff has declined significantly since Kovacic's study in $1980 .{ }^{9}$

Deal's study further confirmed the authors' belief that an important component of the effectiveness of exchanges was the availability of discounts for local university press publications. Deal found that:

1. Six libraries received $20-50 \%$ discounts;

2. One library received discounts of $10 \%$ on monographs and up to $90 \%$ for serials/journals;

3. The six libraries that do not have access to discounts on university press publications accounted for only $30 \%(3,716)$ of the total exchanges $(14,892)$;

4. Three libraries spent less than $\$ 1,000$ purchasing U.S. publications for exchange;

5. Three libraries spent about $\$ 60,000$ on purchasing U.S. publications for exchange. ${ }^{10}$ 
With the arrival of the second author (Trisha Davis) in 1990, the Acquisition Department was able to under-take an extensive evaluation of the exchange operation. By this time, it was clear that funding for a separate gifts and exchanges librarian was unlikely. In addition, the University's administrative emphasis on international programs had diminished, though the Libraries and academic departments still placed considerable emphasis on these areas. This environment was more in line with the thinking of the authors who believed that the University's and Libraries' needs for international material could be met without special emphasis on exchanges. As a corollary to the research done earlier, the authors requested funding in the Fall 1990 to visit two libraries with significant exchange programs - Indiana University and The University of Michigan. This trip confirmed for the authors that OSU had two choices: either invest heavily in exchanges and the staff required to do the job well or minimize the exchange operation. A heavy investment would have involved the following components:

- the designation of staff, including a librarian, to manage and increase the current exchange program;

- the identification of staff with language expertise to communicate with exchange partners;

- the solicitation of new exchange partners;

- the development and monitoring of new arrangements with on-campus suppliers;

- the commitment of time by collection managers with particular subject and language expertise; and

- an increase in costs for the materials budget to purchase material to be exchanged.

The authors believed that minimizing exchanges and focusing existing staff resources in other directions would be most advantageous for the Libraries.

Like many academic libraries, OSU's exchange program was operating under the restrictions of a reduced staff and a severely limited source of free materials to exchange. The availability of funds to acquire these titles as paid subscriptions, however, provided the opportunity for a new approach. Given these parameters, the exchange review project focused on three primary goals: a collection development-based analysis of the value of titles received vs. costs of titles sent; a shift of titles to paid subscriptions whenever possible; and a migration of exchange management functions to fully automated control that is integrated with the local library systems and processes.

\section{Project Proposal}

In May 1991, the Head of the Acquisition Department made a proposal to the Library Materials Budget Committee (which consisted of the Director, Assistant Directors, Budget Officer, Collection Development Officer, and the Head, Acquisition Dept.) to evaluate the exchange program from top to bottom. Particular emphasis would be given to streamlining the exchange process. The following reasons were given:

1. The program was too expensive in staff time and the Libraries no longer had the staff to continue the program at the levels needed. Additional staff would be needed to maintain the existing titles appropriately.

2. The program had not been systematically reviewed from a collection development perspective in at least five years. Who knew what was being received and whether the titles were worthwhile. 
3. The staff position handling exchanges had been vacant for more than one year. The student assistant was able to maintain only basic correspondence duties. Backlogs of exchange materials and handling decisions were building weekly.

4. World changes were making it more feasible and efficient to pay for subscriptions rather than exchange them.

5. The material available to the Libraries for exchange had to be purchased from the University (though at a reduced cost), so the often compelling reason of available free material did not apply.

6. The materials budget as currently funded by the University could withstand additional costs better than the Libraries could withstand additional staff costs. The materials budget was being protected by the University and increased even during the worst serials price increases, so the Libraries had more of a crisis in staffing than in the materials budget.

In essence, the Libraries were already expending funds from the materials budget for titles, so why go through the labor-intensive process of exchanging them?

The Committee agreed to the project with the following guidelines:

1. Acquisition would design a review process that allowed the appropriate collection manager to review each exchange from the perspective of what was being provided to the partner and what the Libraries were receiving in return. This process was intended to assess the value of the titles to the collection.

2. Acquisition would have a free rein to move titles that were to be retained to a purchase status rather than an exchange status even if that process cost the materials budget more. The collection managers would not have to contribute any funds to turn these titles into subscriptions since those costs would be funded centrally. By the same token, if collection managers canceled a title as a result of the review, they would not realize any savings to use for other new titles.

3. The project was expected to require three years so that first priority activities for the Acquisition Department, such as serials check-in and claiming, and for the collection managers, such as approval review and firm order selection, would not be disrupted.

The most significant factor above is the commitment to spend what was needed from the materials budget to more efficiently acquire the material.

\section{Status of the OSU Exchange Program in 1991}

In 1991, when the Libraries made the decision to review and eliminate as many exchanges as possible, 1,721 serial titles were being received on exchange. The majority of these titles could be categorized as periodicals, numbered series, or annuals. The subject areas being most heavily served by the exchange program were biological sciences, agriculture, East Asian studies - particularly Chinese and Japanese, East European/Slavic studies, and geology. The OSU exchange operation was heavily biased toward biology, geology, and agriculture because of the titles available for exchange. Two journals, the Ohio Journal of Science and the Ohio Biological Survey, had been available for exchange to the Libraries for many years, and a significant exchange process had developed using these two titles. Exchanges in East Asian studies and East European/Slavic studies had been developed because of the international focus emphasized in earlier years at OSU. Total dollars spent annually by the Libraries on existing 
exchanges were $\$ 14,554$. Of this amount, $\$ 10,505$ of this amount was spent purchasing 277 copies of the Ohio Journal of Science. In exchange the Libraries received approximately 733 titles. Other titles used for exchange were:

- Theory Into Practice (education)

- Agriculture Experiment Station Bulletin

- Agriculture Experiment Station Circular

- Feminisms (Center for Women's Studies)

- The Journal (the literary magazine of the Ohio State University Department of English)

- News in Engineering

- Ohio Dental Journal

- OSU College of Medicine Journal

- Perkins Observatory Contributions (astronomy)

- Speculum (veterinary science)

- $\quad$ Theatre Studies

Domestic exchanges had proliferated because of the popularity of the Ohio Journal of Science and the Ohio Biological Survey. These domestic exchanges were targeted as an area where significant cancellations or conversions to paid titles would be feasible and more cost effective. In July 1991 before the start of the project, 131 domestic exchanges existed.

\section{Project Design}

Once approval for the project was received, the Acquisition Department proceeded with its usual approach to introducing new procedures or projects - a presentation at the quarterly Collection Managers Forum. The department head had implemented these quarterly meetings for collection managers many years earlier to provide a forum for the Acquisition Department to present issues to their primary clientele, the collection managers. In return, the forums provided an opportunity for discussion of any issues of concern. In addition to presentation of changes already in effect, the forum has been used to discuss new possibilities with collection managers before final decisions are made. In this case, the exchange project was introduced to the collection managers with the details of what they would be expected to do, as well as the policy outlines already approved by the Library Materials Budget Committee.

The forum presentations by the authors covered the history of the exchange program in the past few years, including how it was staffed, when activities occurred, and when and what activities had already been dropped due to staffing cuts. Recent changes that had already been made were also included in the presentation. These changes involved current attempts to mainstream as much of the serials process for exchanges as possible, such as absorbing claim review for these titles into the traditional claim review and processing first issues of new exchange titles in the same workflow as first issues for purchased new titles. As compelling evidence for the new approach to exchanges, the collection managers were reminded of activities that were currently on hold due to staffing cuts: establishing new exchange agreements, adding new titles on existing exchanges, and facilitating monographic exchanges. The authors also discussed their site visits to Indiana and Michigan as background for the current proposal. Finally, the basic outlines of the project were discussed, including distribution of sample documents. The following givens were presented: 
1. As the exchanges were reviewed, their records would be moved from paper files to the online acquisitions system. Online records already existed for the receipt of the individual titles, but no records for the exchange agreements were available online.

2. Collection managers would review each individual exchange agreement in their subject area and make retention or cancellation decisions for each title received.

3. When possible, titles that the collection manager wished to retain would be replaced with a purchased subscription in lieu of the current exchange agreement.

4. Titles would be maintained on exchange only if they could not be purchased or if the cost to purchase was extremely high.

5. Only serials subscription exchanges would be maintained; monographic lists or purchase agreements would not be maintained.

6. Collection managers would not bear the cost of switching a title from exchange status to paid status. In addition, they would not benefit financially by canceling titles either.

Although the collection managers had many questions about the details and especially about the economic consequences to their funds, the project was accepted with enthusiasm. They were promised that the exchange would not be canceled until the paid subscriptions were operational. In other words, once a decision was made to move a title to paid status, the order was placed immediately. Only after receipt of the first piece of the paid subscription was Acquisition free to cancel the exchange.

The project began with a review of the goals for day-to-day management of exchanges. For existing titles received on exchange, the subscriptions would continue to be maintained according to standard procedures until the review process was complete for that title. Missing issues would continue to be claimed, but no problem resolution would be done on subscriptions that had lapsed until a retention decision was made. Any correspondence received was answered with a generic letter explaining the status of the program review. For existing exchange agreements, any letters of inquiry were answered with a form letter explaining the review project and supplying only a confirmation list of titles sent and received on exchange. Correspondence concerning existing exchanges or requests for additional titles were simply filed away for consideration later, after the exchange decisions were complete. Inquiries regarding the establishment of new exchanges were ignored.

The next step was an inventory of files and material on hand in order to provide supporting information for the collection managers. The department had built massive paper files of correspondence dating back decades. The paperwork was poorly labeled and organized; it was stored by geographic location of the partner. Although some information was helpful for investigation, the content was generally out of date and irrelevant. The name and address information usually was obsolete, and the master card files were not adequately updated. As each file was pulled for examination, the name of the exchange partner was established by searching in local and national authority files so the exchange analysis documents and data in the new online files would coordinate with other acquisition activities for that institution. The backlog of unidentified exchange pieces that had accumulated was sorted, searched, and forwarded to the collection manager reviewing that area of exchanges. No attempt was made to resolve questions concerning possible "comes-with" pieces or items received without explanation.

The review project procedures were designed by the Head of the Continuation Division of the Acquisition Department and her staff. The first sample form, which later became known as the EPDAS (Exchange Project Data Analysis Sheet), provides the detailed information for each 
exchange (see appendix A). The EPDAS included the name of the exchange partner, the date the exchange was initiated, information on which titles were sent by OSU and their cost. The EPDAS also included information on the titles received from the partner, library location of the titles, call number, and subscription status. Availability information such as cost was included only if it was found in the initial search. The last line on each listing was to be circled: continue subscription or eliminate from exchange. Finally, the collection manager was asked to add any other comments and to sign and date the form. They were given a due date for a time period agreed upon earlier at the Collection Managers' Forum.

These documents were prepared for each exchange by Acquisition staff. If the exchange covered more than one subject area, it was sent to each collection manager involved but included only the titles for which they had collection development responsibility. This allowed each collection manager to review only the titles in their areas. Before the form was sent, the titles were searched in standard sources such as vendor databases and other catalogs. No additional investigation was done at this point. If the collection manager wanted to keep the title, Acquisition would do more extensive searching. The authors felt that many of the titles would be canceled at the outset and there was no need to do extensive searching until the cancel/keep decision had been made. The decision for the collection manager was whether to keep the title or not. Acquisition made the decision about whether the exchange should be maintained or whether paid subscriptions could be initiated.

When the EPDAS were returned from the collection managers, work began in the Acquisition Department to review the results and determine the appropriate course of action. A staff worksheet was attached to each EPDAS returned to record the subsequent actions taken with regard to the exchange agreement and the specific titles. Subsequent actions included:

For exchanges being completely canceled:

1. notify OSU suppliers to cancel the shipment of a title as of a certain date;

2. notify the exchange partner of the cancellation of the agreement;

3. advise the exchange partner on correct method to subscribe to canceled exchange titles.

For exchanges being changed entirely to paid subscriptions:

1. establish new paid subscriptions;

2. cancel the exchange title when first piece of new paid subscription is received;

3. when all paid titles are confirmed, notify the exchange partner of the cancellation of the agreement;

4. advise the exchange partner on correct method to subscribe to canceled exchange titles.

For exchanges being partially canceled or changed to paid subscriptions:

1. contact exchange partner to determine if partial exchange is feasible, or to determine if titles can be purchased rather than exchanged, and at what cost;

2. determine cost and availability of paid subscriptions;

3. evaluate cost to exchange vs. cost of paid subscriptions;

4. establish new paid subscriptions;

5. revise or cancel exchange agreement as appropriate. 
For titles being maintained on exchange:

1. send letter of confirmation to exchange partner for titles to be maintained on exchange;

2. request replies verifying titles exchanged, a current address, and contact person.

For all actions taken:

1. update OSU records with action taken;

2. notify the collection manager of action taken.

Form letters to cover most of these circumstances were developed to expedite the paperwork associated with the project. These included forms to cancel the exchange, maintain the exchange, explain any changes to the OSU supplier, and initiate a partial cancellation (see Forms 1-3). Special records were designed for the online system to record the exchange agreements as well as the records for the individual titles.

In addition, a statistical form was developed to record the current status of each agreement under review and to provide cumulative statistics. This report listed each exchange by name under the category of its current status within the project. For example, titles could be:

- out for review (in the hands of the collection manager);

- in process (collection manager has made decision; activity ongoing in the Acquisition Department);

- maintained (decision to maintain has been made; statistics include number of titles sent to partner and their costs and number of titles received from the partner);

- canceled (exchange has been canceled; statistics include number of titles canceled and cost of titles canceled); or

- changed to paid (titles being moved from exchange to paid subscriptions; statistics include titles canceled on exchange and their cost on exchange as well as number of titles ordered as paid subscriptions and their cost).

This spreadsheet was printed regularly to provide a status report of the project. 


\section{University Libraries}

1858 Neil Avenue Mall

Columbus, OH 43210-1286

Phone 614-292-6151

FAX (Adm) 614-292-7859

FAX (ILL) 614-292-3061

January 12, 1995

Tulane University Library

Serials Section-Exchanges

Acquisitions Department

New Orleans, LA 70118

Dear Exchange Partner:

In past years our library has maintained an exchange agreement with your institution. After an extensive review of our program, we have decided to discontinue this exchange.

Please remove us from the exchange mailing list for the following publication:

Tulane Studies in English

Tulane Studies in Philosophy

We will no longer be sending you the following publication(s):

\section{Ohio Journal of Science}

News in Engineering

Ohio Biological Survey Bulletin

We appreciate the cooperation we have received from you through our exchange program.

Sincerely,

Teresa Hagerman

Exchange Specialist

fax no. 614-292-2015

Form 1. Sample Cancellation Letter

University Libraries $\quad 1858$ Neil Avenue Mal]

Columbus, $\mathrm{OH} 43210-1286$

Phone 614-292-6151

FAX (Adm) 614-292-7859

FAX (ILL) 614-292-3061

[date]

[address]

Dear Exchange Partner:

We have maintained an exchange agreement with your institution for several years. We are in the process of updating our records and would like you to confirm the following information:

- Address for correspondence (including name of contact person)

- Address for publications, if different from address for corressondence

- Publications you send to us on exchange

- Publications you receive from us on exchange

- Fax Number

The information we have requested is essential for the efficiency and proper functioning of the exchange program. Please return form before [date]. Your cooperation is greatly appreciated.

Sincerely,

Teresa Hagerman

Exchange Specialist

Form 2. Sample Exchange Confirmation Letter 


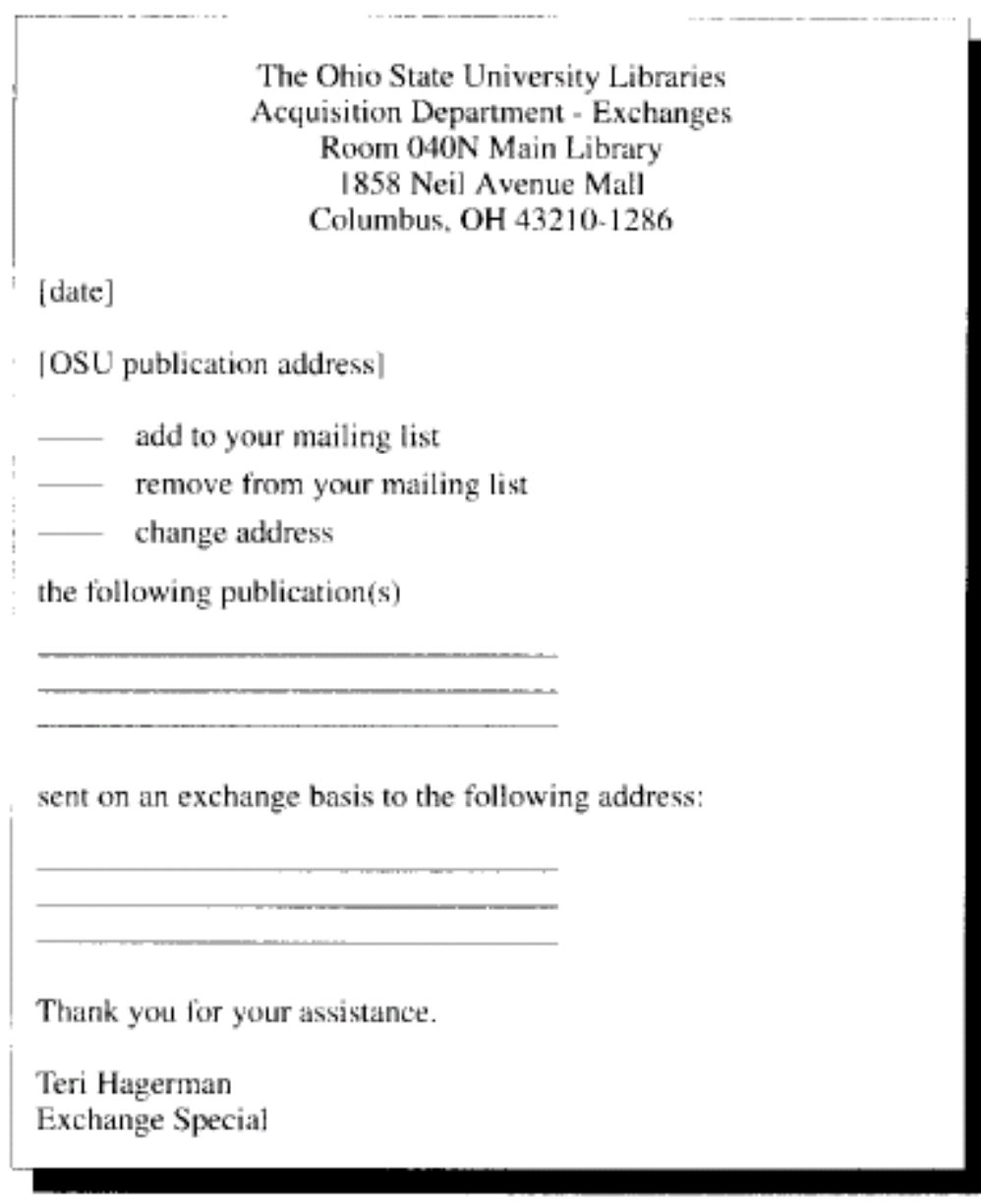

\section{Form 3. Sample OSU Publication Notification Form}

\section{Interaction with Campus Publishing}

As part of the project design and implementation, the authors and Acquisition staff met with each of the presses/publishers on campus from whom titles were purchased for exchange. The review process and its rationale were explained. The expected results - that a large number of titles would be canceled - were discussed. To soften the consequences of these cancellations, the review had been specifically designed to give these publishers as much advance notice as possible. For example, all of a publisher's titles would be reviewed as a group in the spring so that they could be notified of the number to be canceled several months before the renewal was to have occurred. They advised us of their schedules to determine when they would need to be advised in order to plan their budgets. In addition, every time we canceled an exchange where we were supplying a title from OSU, we sent subscription information to the partner with the cancellation notice. The information was intended to encourage the exchange partner to resubscribe on its own. In the case of the Ohio Journal of Science, the publisher provided us with prints of their publication information to be included (see Form 4). One of the most interesting aspects of the project for the Libraries was that, in several cases, the press/publisher contacted the Libraries before we could contact them. The University was under significant budget stress 
so the publishers were contacting us to renegotiate our prices. It was fortuitous that this project was already in the design phase. Had it not been, we would still have had to respond to those changing circumstances without a well-designed process in place. In one case, the Ohio Biological Survey was providing us with 200 subscriptions at no charge. With expected budget cuts, they could no longer provide these subscriptions free. Initially, they wanted to raise the price per subscription from gratis to the full $\$ 60$ price. The Libraries' compromise offer was to request qualification for the bookseller's discount of $40 \%$, which reduced the per-title price to $\$ 36$ during the term of the project.

In another case, the staff of Theory Into Practice, published by the Education Department, was threatening to cancel all of the subscriptions they supplied for us at no cost. We reached an agreement that they would continue to supply us with these subscriptions for a year while we finished our review. On a more permanent basis, they agreed to supply us with the copies at no cost if, in return, we would relieve them of the job of mailing out the quarterly issues. Thus, we absorbed the administrative job of actually packaging and sending the issues of the journals out to our existing partners. We provided the envelopes and labor and asked only that the Education Department provide mailing labels printed from their database. Their administrative person did that once, and then promptly deleted the address file! This setbackhaving to rekey the addresses in our own database - confirmed our goal of eliminating as many of those exchanges as possible. 


\section{THE OHIO JOURNAL OF SCIENCE}

The Ohio Journal of Science

$1500 \mathrm{~W}$. Third Ave. Suite 223

Columbus, $\mathrm{OH} 43212-2817$ U.S.A.

Phone or Fax: (614) 488-2228

1996 Volume No 96

Number Issues per Year: 5

Frequency: 5 times a year

ISSN: 0030-0950

Months of Publication: Mar., Apr., June, Sept., Dec.

\section{RATES} Subscriptions are entered for the calendar year

Subscription:

\begin{tabular}{ccc} 
U.S.A & $\begin{array}{c}\text { Other } \\
\text { Countries }\end{array}$ & $\begin{array}{c}\text { Agent } \\
\text { Discount }\end{array}$ \\
\hline 550.00 & $\$ 55.00$ & None \\
\multicolumn{3}{c}{ Inctudes normal shipping) } \\
\multicolumn{3}{c}{ Do not airmail }
\end{tabular}

AIRMAIL DELIVERY CHARGE ADVANCE PAYMENT IN U.S. DOLLARS REQUIRED

BACK ISSUES:

Availability:

Prices:

Most issues available.

$\$ 10.00$ subscribers $-\$ 12.00$ others per issue.

DESCRIPTION: The Ohio Journal of Science considers original contributions from members and non-members of theAcademy in all fields of science. Special consideration will be given to Ohioana. Submission of an article is understood to mean that the article is original and unpublished and is not being considered for publicatoin elsewhere. All manuscripts will be critically reviewed. It should be understood that the opinions expressed by the reviewers are their own, and do not represent the views of The Ohio Academy of Science or The Ohio Journal of Science. Manuscripts and illustrations should be preparedin triplicate in accord with instructions published in at least one issue each year and submitted to Dr. Thomas W. Schmidlin, Editor, The Ohio Journal of Science, Kent State University, Dept. of Geography, Kent, OH, 44242, U.S.A.

ADVERTISING ACCEPTED: Yes

RENTAL USE OF MAILING LIST: YeS

THIS JOURNAL IS ABSTRACTED

AND/OR INDEXED IN: Bibliography of Agriculture, Biological Abstracts, Chemical Abstracts, Current Contents, Environmental Information Center, Forestry Abstracts, Geology Abstracts, Horticulture Abstracts, Nuclear Science Abstracts, Selected Water Resources Abstract

\section{Form 4. Sample Publication Information Form}




\section{Revised and Integrated Workflows}

Two additional goals of this project were to 1) sort through and eliminate much of the material in the existing paper files, and 2) for those exchanges retained, transfer as much information as possible into records in the online system. At the beginning of the project, the old files were reviewed for information needed to make the project decisions. Items that were obviously outdated were discarded unless they were the most recent documentation we had. The only correspondence retained at that point in the project included letters of agreement, title lists, and several years of the most recent communications. As retention decisions were made, these paper files were reviewed a second time. For canceled exchanges, we discarded all but the most recent correspondence from the exchange partner and added copies of the project documents, such as the EPDAS and cancellation letters. For exchanges maintained, we weeded all but the most current documents and added a copy of the EPDAS.

Now the primary resource for information on the existing exchanges is OSCAR, the Libraries' online system. For each exchange partner, we established a master exchange record, which is actually a set of locally produced bibliographic and order records. The bibliographic record is very brief. The name of the exchange partner serves as a corporate author entry. The title for each master record reads: Exchange Agreement. The imprint information reflects only the city and state of the exchange partner (see Figure 1, Sample Record).

Two internal notes in the order record store information specifying which titles are sent to and received from that exchange partner. For each title received, a standard set of bibliographic, order, and check-in records are set up. The order and check-in records indicate that the title is received as an exchange and refer back to the master exchange records. The master order record also indicates which collection managers and which library locations participate in the exchange. These data allow any staff member to search the system by title, location, or collection manager to collect all records associated with that exchange.

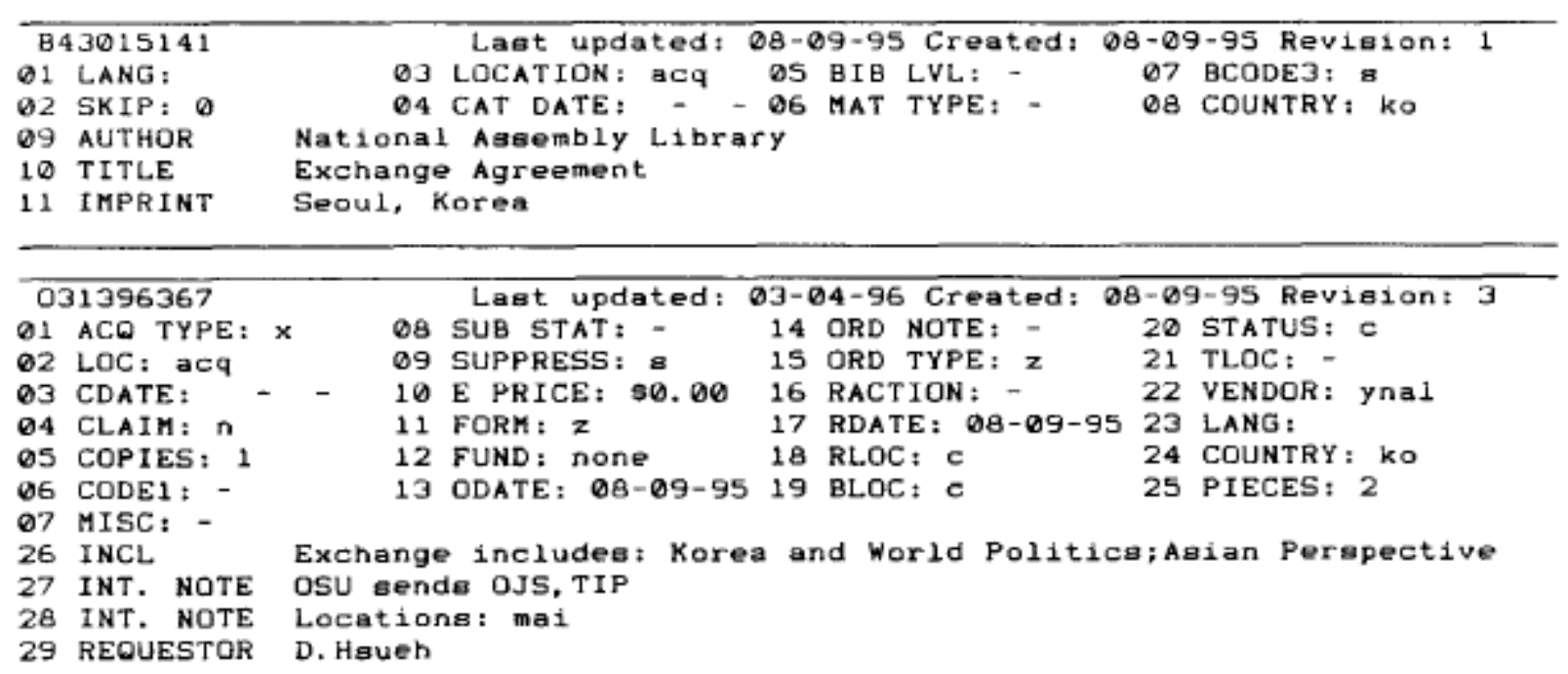

\section{Figure 1. Sample Bibliographic and Order Records}




\section{Statistical Analysis and Results}

Completion of the review process occurred in three years, as predicted. The completion of all details associated with the project will likely take an additional year. The project has succeeded in streamlining our operations and reducing our costs beyond expectations. This streamlined exchange program can be maintained by the existing staff who maintain all other continuation activities in the department. As was expected, on careful review, many of the titles were found to be "not worth the paper they were printed on." Many entire exchanges were simply canceled. For the majority of the titles on exchange that were still wanted, it was possible and more feasible to enter regular paid subscriptions. This was almost universally true for domestic exchanges, which had mushroomed over the years due to the popularity of the Ohio Biological Survey and the Ohio Journal of Science. The costs for the titles retained as paid subscriptions are not significantly higher than the costs for the titles that had been purchased to send on exchange to the partners. The foreign exchanges had a higher retention rate, particularly in areas of the world where hard currency is difficult to obtain. In some predictable areas (such as the former Soviet Union), it was still appropriate to continue the exchanges. Unfortunately, these are still the most problematic ones since the partners often want unusual arrangements such as deposit of funds in an account with a U.S. publisher for them to purchase U.S. material.

The process of reviewing each agreement with exchange partners and the investigation of pricing and availability options revealed trends that supported the decision to reduce exchanges. During the course of the project, letters of inquiry from exchange partners were received regularly. Many of these inquiries occurred because the partner also was reviewing its exchange operations. Some partners were simply canceling all exchange operations while others offered their titles on subscription to academic institutions at no cost or were willing to establish mailing lists rather than subscriptions. It was often difficult for U.S. academic and research institutions to identify and locate the appropriate staff handling exchanges. Many partners had reorganized their exchange activities and appeared to have lost track of OSU's agreement. These difficulties only reinforced the perception that exchanges had become too costly and time consuming to maintain for all parties.

Statistics were gathered continuously throughout the three-year project. The historical files were all manual, with data recorded on $3 "$ x 5" cards or written on file folders holding related correspondence. The initial data collection was done manually, by literally counting notes on each card and file folder. When the final statistics were gathered at the end of March 1996, for this publication (see Table 1), fifteen exchanges were awaiting completion at various stages within the project. At that time, the Libraries had reduced the number of exchanges by $90.5 \%$ to sixty-seven; only two of these (3\%) were domestic partners, and the remaining sixty-five (97\%) were foreign partners. The majority of these exchanges (including the two domestic ones) were retained because the individual serial titles were not available as paid subscriptions. The number of titles sent to exchange partners dropped $91 \%$ to 105 . Currently, the cost per exchange varies significantly for domestic and foreign, but due to the extreme reduction in the number of domestic exchanges, the comparisons are highly skewed.

A further analysis of the exchanges retained as of March 1996 reveals some meaningful variances based on the institutional nature of the exchange partner. The sixty-seven exchanges were divided into four broad categories. Twenty-three (34\%) of the current exchange partners are universities or university libraries. Examples of this category are Kuwait University, National Taiwan University, and Kyoto University Library. These twenty-three partners account for approximately $34 \%$ for the total and average number of titles sent and received. The average cost 
of these exchanges is somewhat lower than the average cost for all exchanges: $\$ 26.35$ per exchange, or $\$ 6.72(20 \%)$ less. Analyzed on a per-title basis, the average cost-per-title sent is $22 \%$ lower and the average cost-per-title received is $25 \%$ lower. University-related exchanges are the least costly to maintain, in our experience.

A second major category of exchange partners can be described as national, state, or regional libraries, such as the National Library of Australia and the Federal University of Parana. This small group of twelve exchange partners represents only $18 \%$ of the total exchanges remaining, but eighty-four (26\%) of the total number of titles received. The average number of titles received is seven, almost $150 \%$ higher than the overall average of 4.79 . The average number of titles sent also is slightly higher, 1.83 as compared to 1.57 . The costs of sending titles is $\$ 17.27$, almost as low as the costs for university-related exchanges. Exchanges with this type of government library appear to be worthwhile in terms of cost and the number of titles received.

The largest category of exchange partners includes special libraries, associations, and university departments whose activities are focused on a particular subject area. For OSU, this category includes twenty-six (39\%) exchange partners, such as the New Zealand Oceanographic Institute, the National Institute of Polar Research, and the International Society for Educational Information. Both the total and average number of titles sent are slightly lower than average for this category. The number of titles received, eighty-five (26\%), however, is substantially lower, and the average number of titles received, 3.27, is the lowest of all categories, $32 \%$ lower than the overall average. These ratios are reflected in the total cost of $\$ 990.00$, or $45 \%$ of the entire exchange budget for $26 \%$ of the titles received. In fact, the average cost-per-title received is $\$ 11.65$, almost $70 \%$ higher than the average $\$ 6.90$. For the OSU Libraries, this type of exchange is particularly costly and results in the fewest titles received.

The final category of exchange partners is research academies and institutes, such as L'Academie Royale de Belgique and the Intercultural Research Institute. These six exchanges represent only $9 \%$ of the exchanges and $11 \%$ of the costs. The only significant characteristic of this exchange category is a slightly higher-than-average cost per exchange: $\$ 40.00$, or $20 \%$ higher. Considering the size of the category, these tables may not represent any significant factors relevant to other libraries.

The primary reasons for complete cancellation of a foreign exchange (excluding cancellation in order to change to paid subscriptions) were higher than average costs to maintain the exchange, the cancellation of the exchange by the partner, or the cancellation of the exchange based on a collection development decision by the collection manager. The number of exchanges canceled because the titles received could be changed to paid subscriptions was 273 , or $39 \%$ of the beginning collection. Like the analysis of the exchanges that were completely canceled, the domestic and foreign ratio was slightly tilted toward domestic exchanges. A total of seventy-six domestic (28\%) and 197 foreign (72\%) exchanges were changed to paid, as compared to the $21 / 79 \%$ ratio at the beginning of the project. When the costs of replacing the exchanged titles with paid subscriptions were analyzed, the subscription costs were lower. To maintain domestic exchanges cost an average $\$ 24.58$ per title on exchange, but only $\$ 20.05$ as a paid subscription. For foreign titles, the average cost per title was $\$ 54.47$ on exchange, but only $\$ 51.62$ as a paid subscription. For the Libraries this was a significant factor in the decision to move more than 400 titles to paid subscriptions (see Tables 2 and 3 ). 
Table 1: Post-Project Serials Exchanges, March 1996

\begin{tabular}{lccccccc}
\hline & $\begin{array}{c}\text { Number of } \\
\text { Exchanges }\end{array}$ & $\begin{array}{c}\text { Number of } \\
\text { Titles Sent }\end{array}$ & $\begin{array}{c}\text { Number of } \\
\text { Titles } \\
\text { Received }\end{array}$ & Cost & $\begin{array}{c}\text { Average } \\
\text { Cost per } \\
\text { Exchange }\end{array}$ & $\begin{array}{c}\text { Average } \\
\text { Cost per } \\
\text { Title Sent }\end{array}$ & $\begin{array}{c}\text { Average Cost } \\
\text { per Title } \\
\text { Received }\end{array}$ \\
\hline $\begin{array}{c}\text { Domestic } \\
\text { Statistics }\end{array}$ & 2 & 5 & 4 & $\$ 136.00$ & $\$ 68.00$ & $\$ 27.00$ & $\$ 34.00$ \\
$\begin{array}{c}\text { Foreign } \\
\text { Statistics }\end{array}$ & 65 & 100 & 317 & $\$ 2,080.00$ & $\$ 32.00$ & $\$ 20.80$ & $\$ 6.56$ \\
Total & 67 & 105 & 321 & $\$ 2,216.00$ & $\$ 33.07$ & $\$ 21.10$ & $\$ 6.90$ \\
\hline
\end{tabular}

Table 2: Exchanges Cancelled

\begin{tabular}{lccccccc}
\hline & $\begin{array}{c}\text { Number of } \\
\text { Exchanges }\end{array}$ & $\begin{array}{c}\text { Number of } \\
\text { Titles Sent }\end{array}$ & $\begin{array}{c}\text { Number of } \\
\text { Titles } \\
\text { Received }\end{array}$ & Cost & $\begin{array}{c}\text { Average } \\
\text { Cost per } \\
\text { Exchange }\end{array}$ & $\begin{array}{c}\text { Average } \\
\text { Cost per } \\
\text { Title Sent }\end{array}$ & $\begin{array}{c}\text { Average Cost } \\
\text { per Title } \\
\text { Received }\end{array}$ \\
\hline $\begin{array}{l}\text { Domestic } \\
\text { Exchanges } \\
\text { Cancelled }\end{array}$ & 46 & 76 & 134 & $\$ 1,094.00$ & $\$ 23.78$ & $\$ 14.39$ & $\$ 8.16$ \\
$\begin{array}{c}\text { Foreign } \\
\text { Exchanges } \\
\text { Cancelled }\end{array}$ & 128 & 177 & 349 & $\$ 6,188.00$ & $\$ 48.34$ & $\$ 34.96$ & $\$ 17.73$ \\
$\begin{array}{c}\text { Exchange } \\
\text { Agreements } \\
\text { Cancelled }\end{array}$ & 174 & 253 & 483 & $\$ 7,282.00$ & $\$ 41.85$ & $\$ 28.78$ & $\$ 15.08$ \\
\hline
\end{tabular}

Table 3: Titles Changed to Paid Subscriptions

\begin{tabular}{lccccccc}
\hline & $\begin{array}{c}\text { Number of } \\
\text { Exchanges }\end{array}$ & $\begin{array}{c}\text { Number } \\
\text { of Titles } \\
\text { Sent }\end{array}$ & $\begin{array}{c}\text { Number of } \\
\text { Titles } \\
\text { Received }\end{array}$ & Cost & $\begin{array}{c}\text { Average } \\
\text { Cost per } \\
\text { Exchange }\end{array}$ & $\begin{array}{c}\text { Average } \\
\text { Cost per } \\
\text { Title Sent }\end{array}$ & $\begin{array}{c}\text { Average Cost } \\
\text { per Title } \\
\text { Received }\end{array}$ \\
\hline $\begin{array}{c}\text { Domestic } \\
\text { Exchanges }\end{array}$ & 46 & 76 & 134 & $\$ 1,094.00$ & $\$ 23.78$ & $\$ 14.39$ & $\$ 8.16$ \\
$\begin{array}{c}\text { Cancelled } \\
\text { Foreign } \\
\text { Exchanges } \\
\text { Cancelled }\end{array}$ & 128 & 177 & 349 & $\$ 6,188.00$ & $\$ 48.34$ & $\$ 34.96$ & $\$ 17.73$ \\
$\begin{array}{c}\text { Exchange } \\
\text { Agreements } \\
\text { Cancelled }\end{array}$ & 174 & 253 & 483 & $\$ 7,282.00$ & $\$ 41.85$ & $\$ 28.78$ & $\$ 15.08$ \\
\hline
\end{tabular}


Table 4: Titles Changed to Paid Subscriptions

\begin{tabular}{|c|c|c|c|c|c|c|c|}
\hline & $\begin{array}{l}\text { Number of } \\
\text { Exchanges }\end{array}$ & $\begin{array}{c}\text { Number } \\
\text { of Titles } \\
\text { Sent }\end{array}$ & $\begin{array}{c}\text { Number of } \\
\text { Titles } \\
\text { Received }\end{array}$ & Cost & $\begin{array}{c}\text { Average } \\
\text { Cost per } \\
\text { Exchange }\end{array}$ & $\begin{array}{c}\text { Average } \\
\text { Cost per } \\
\text { Title Sent } \\
\end{array}$ & $\begin{array}{c}\text { Average } \\
\text { Cost per Title } \\
\text { Received } \\
\end{array}$ \\
\hline $\begin{array}{l}\text { Titles changed to paid } \\
\text { subscriptions }\end{array}$ & 273 & 702 & 414 & & & & \\
\hline $\begin{array}{l}\text { Cost of items sent on } \\
\text { exchange }\end{array}$ & & & & $\$ 18,456.00$ & $\$ 67.60$ & $\$ 26.29$ & $\$ 44.58$ \\
\hline Cost of titles as paid subs & & & & $\$ 17,045.00$ & $\$ 62.43$ & & $\$ 44.17$ \\
\hline $\begin{array}{l}\text { Domestic titles changed to } \\
\text { paid subscriptions }\end{array}$ & 76 & 167 & 137 & & & & \\
\hline $\begin{array}{l}\text { Cost of items sent on } \\
\text { exchange }\end{array}$ & & & & $\$ 3,366.00$ & $\$ 44.29$ & $\$ 20.16$ & $\$ 24.58$ \\
\hline Cost of titles as paid subs & & & & $\$ 2,74 ;, 110$ & $\$ 36.14$ & & $\$ 20.05$ \\
\hline $\begin{array}{l}\text { Foreign titles changed to } \\
\text { paid subscriptions }\end{array}$ & 197 & 535 & 277 & & & & \\
\hline $\begin{array}{l}\text { Cost of items sent on } \\
\text { exchange }\end{array}$ & & & & $\$ 15,090.00$ & $\$ 76.70$ & $\$ 28.21$ & $\$ 54.47$ \\
\hline Cost of titles as paid subs & & & & $\$ 14,298.00$ & $\$ 72.58$ & & $\$ 31.62$ \\
\hline
\end{tabular}

\section{Conclusion}

This statistical review illustrates strongly that a collection development review was warranted. The Acquisition Department used cost analysis and the goal of streamlining operations as a tool to facilitate this collection development review. All three goals for the project - a collection development - based analysis of the value of titles received vs. costs of titles sent, a shift of titles to paid subscriptions whenever possible, and a migration of exchange management functions to fully automated control that is integrated with the local library system and processes-were met and proved to be of value to the exchange program.

Library collections are dynamic and ever changing. A collection development-based analysis of the exchange agreements should be performed on any exchange title on a regular basis. The initial gathering of information about the titles sent and received highlights any changes to the exchange agreement that would upset the balance. Such problems as late or missing issues, lack of response to inquiries and claims, and general difficulties in communications with the exchange partner can be identified and addressed. Should the library discover significant changes to any side of the exchange equation, this analysis would provide the momentum and data needed to renegotiate or cancel the exchange.

The shift of exchanged titles to paid subscriptions proved fiscally beneficial for the OSU Libraries. In most cases, the cost of titles sent was not significantly higher than the cost of paid subscriptions and those titles were, in fact, available on subscription. Other libraries may not have the funding for paid subscriptions or may have a wealth of titles to offer in exchange. In such cases, the decision to maintain exchange agreements would be based on other factors, such as the availability of staffing.

The migration of exchange functions to fully automated control that is integrated with the local library system and processes is required for the efficient management of exchanges. In most major academic libraries, exchange activities originated well before any in-house automation and usually were maintained separately from normal acquisition activities. Any library managing exchanges should use the review process to streamline its files, build an 
automated control system, and create as many links as possible with the library's online systems. The benefits to access, productivity, fiscal and bibliographic control, and management statistics far outweigh the resources needed to convert the files.

\section{Notes}

${ }^{1}$ Mark Kovacic, "Acquisition by Gift and Exchange," in Acquisition of Foreign Materials for U.S. Libraries, 2d ed. By Theodore Sanders. (New York: Scarecrow Press, 1982): 37-41.

${ }^{2}$ William H. Huff, "Acquisition of Serial Publications," Library Trends 18(January 1970): 308.

${ }^{3}$ Pamela Bluh and Virginia C. Haines, "The Exchange of Publications: An Alternative to Acquisitions," Serials Review 5(1979): 103.

${ }^{4}$ Ibid., 104.

5 Priscilla C. Yu, "Cost Analysis: Domestic Serials Exchanges," Serials Review 8(Fall 1982): 79.

${ }^{6}$ Letter to William J. Studer, Director of Libraries, The Ohio State University Libraries, from Francille M. Firebaugh, Vice Provost for International Affairs, The Ohio State University, 27 July 1988.

${ }^{7}$ Mark Kovacic, "Gifts and Exchanges in U.S. Academic Libraries," Library Resources and Technical Services 24(Spring 1980): 160.

${ }^{8}$ Association of Research Libraries, Office of Management Studies. "The Gifts and Exchange Function in ARL Libraries." Systems and Procedures Exchange Center (SPEC) Kit and Flyer \#117, Washington, DC: Association of Research Libraries, 1985: 59.

${ }^{9}$ Carl Deal, "The Administration of International Exchanges in Academic Libraries: A Survey," Library Acquisitions: Practice \& Theory 13(1989): 201 -202.

${ }^{10}$ Ibid., 202-203. 


\section{APPENDIX A: SAMPLE EPDAS FORM}

Chicago Academy of Sciences (YCAS)

Exchanged initiated: $2 / 58$

OSU sends:

Price

$\$ 38$

$\$ 38$

\section{Cost to OSU}

$\$ 38$

$\$ 38$

Totals: 1 title

III\# .031234468

ISSN 0009-3491

HSS Bulletin

Call no. Q11C52

Subscription status: Irregular; last piece received 1/90

Availability: Faxon $\$ 2.00$

\section{Continue Subscription or Cancel}

HSS Natural History Miscellanea

Call no QH1C5

III\# .031222892

ISSN 0096-9109

Subscription status: Irregular; last piece received $6 / 84$

Availability: Faxon $\$ .60 /$ piece

\section{Continue Subscription or Cancel}

Comments:

Reviewed by:

Date:

Recommendations due by $2 / 1 / 92$. For questions or additional information please call Jeff Kompier at 2-6314.

Please return this form to:

Jeff Kompier

Continuation Acquisition Div.

Main Library $040 \mathrm{~N}$ 